\title{
Should Dialysis be Offered to All Elderly Patients?
}

\author{
Michael J. Germain \\ Baystate Medical Center and Tufts University, Springfield, Mass., USA
}

\author{
Key Words \\ Dialysis · Elderly · Withdrawal · Conservative care $\cdot$ Palliative \\ care $\cdot$ Ethics
}

\begin{abstract}
Nephrologist are often faced with the question of the appropriate initiation and withdrawal from dialysis. Many clinicians feel that patient should be offered dialysis when they have ESRD regardless of the potential risks vs. benefits. My position in this debate is that nephrologists have the obligation to order treatments that are indicated and effective for their patients and will provide more benefit that harm. They should not order dialysis in patient that are not likely to benefit from the treatment. Patients have the right to refuse treatments but not the right to demand that a clinician order an ineffective treatment. Shared decision making is the key principle in deciding on the initiation and withdrawal from dialysis. The national guideline; Shared Decision Making: The Appropriate Initiation and Withdrawal from Dialysis supports this approach.

๑) 2015 S. Karger AG, Basel
\end{abstract}

As physicians we take an oath to 'first do no harm.' We also are obligated to avoid suffering whenever possible.

For some patients, elderly or not, dialysis will do more harm than good and will result in suffering.
(C) 2015 S. Karger AG, Basel

0253-5068/15/0393-0055\$39.50/0
There is a common misunderstanding among the public and medical professionals that patients have a right to receive a medical treatment if they ask for it and the clinician must order it. Patients have the right to refuse medical treatments; they do not have the right to compel a clinician to order a treatment that the clinician feels would not be effective or would cause more harm than good.

The current standard for clinical decision making is shared decision making (SDM). This forms the basis of our national nephrology guidelines - Shared Decision Making in the Initiation and Withdrawal from Dialysis [1]. SDM starts with understanding our patient's goal and desires for care. Estimation and communication of prognosis (see companion article) is followed by the development of Advanced Care Planning. When there is no agreement on the Goals of Care (GOC), then the guidelines suggest steps to accomplish conflict resolution. Ultimately, SDM is a process of consensus and not everyone will end up at their original positions and each party will learn from the others' views to develop the (hopefully) best GOC.

If it is not possible to arrive at a consensus, then the guidelines are quite clear that the clinician is not obligated to order dialysis if they do not feel it is indicated. The guidelines list the situations where dialysis is not appropriate (box 1).

When the clinician and/or patient has significant uncertainty as to whether dialysis will be of benefit, a Time 
Box 1. From renal physicians association. Shared decision-making in the appropriate initiation of and withdrawal from dialysis [1]

Recommendation No. $5^{*}$

If appropriate, forgo (withhold initiating or withdraw ongoing) dialysis for patients with AKI, CKD, or ESRD in certain, welldefined situations.

These situations include the following:

- Patients with decision-making capacity, who being fully informed and making voluntary choices, refuse dialysis or request that dialysis be discontinued.

- Patients who no longer possess decision-making capacity who have previously indicated refusal of dialysis in an oral or written advance directive.

- Patients who no longer possess decision-making capacity and whose properly appointed legal agents/surrogates refuse dialysis or request that it be discontinued.

- Patients with irreversible, profound neurological impairment such that they lack signs of thought, sensation, purposeful behavior, and awareness of self and environment.

Recommendation No. 6

Consider forgoing dialysis for AKI, CKD, or ESRD patients who have a very poor prognosis or for whom dialysis cannot be provided safely.

Included in these categories of patients are the following:

Those whose medical condition precludes the technical process of dialysis because the patient is unable to cooperate (e.g., advanced dementia patient who pulls out dialysis needles) or because the patient's condition is too unstable (e.g., profound hypotension). Those who have a terminal illness from non-renal causes (acknowledging that some in this condition may perceive benefit from and choose to undergo dialysis).

Those with stage $5 \mathrm{CKD}$ older than age 75 who meet two or more of the following statistically significant very poor prognosis criteria (see Recommendations No. 2 and 3):

1) Clinicians' response of 'No, I would not be surprised' to the 'surprise' question;

2) High comorbidity score;

3) Significantly impaired functional status (e.g., Karnofsky Performance Status score less than 40); and

4) Severe chronic malnutrition (i.e., serum albumin less than $2.5 \mathrm{~g} / \mathrm{dl}$ using the bromcresol green method).

* Medical management incorporating palliative care is an integral part of the decision to forgo dialysis in AKI, CKD, or ESRD, and attention to patient comfort and quality of life while dying should be addressed directly or managed by palliative care consultation and referral to a hospice program (see Recommendation No. 9 on palliative care services).

Limited Trial (TLT) is recommended by the guidelines. A TLT should not be a way to avoid full discussion of prognosis and the potential benefits and harms of dialysis. If a TLT is undertaken, it should be in the form of a written contract, which spells out the timeline and milestones that should be achieved with the understanding that dialysis will be stopped if the set milestones are not achieved [2].

Currently in North America, dialysis is the default treatment method when the eGFR starts to drop below 10 $\mathrm{ml} / \mathrm{min}$. This practice has been driven by the mistaken opinion that there is a benefit to 'early' dialysis before the patient has the traditional indications for initiation of dialysis [3]. Financial factors are also likely to play a part with more elderly patient initiating, and higher eGFRs at initiation of dialysis, in high health care cost areas where there is a greater density (competition) of nephrologists [4].
This practice has been called into question based on the recently published randomized control trial, which did not demonstrate a benefit to an early start [5].

Based on other studies, the case has been made that in some patients an early start to dialysis may do more harm than good. The complications of vascular access, the negative effect of dialysis on residual renal function, the stress of dialysis on the myocardium, and the negative effects on quality of life may result in higher morbidity and mortality [6].

Conservative management (CM), the planned non-dialytic treatment of advanced CKD in mostly elderly patients, has been systematically studied in the United Kingdom, Italy, and Australia for a number of years. These prospective controlled studies demonstrate that for a patient $>75$ with comorbidities, especially ischemic heart disease, dialysis does not appear to offer a survival 
advantage over CM. Furthermore, quality of life deteriorates with the initiation of dialysis and does not return to baseline. The CM patients maintain a stable quality of life till one or two months prior to death. Very few CM patients have progressive uremia since the elderly often have very slow deterioration in eGFR [7-11].

It may be that eGFR is not the best estimate to assess the overall renal function. Some uremic toxins ( $\mathrm{p}$ creosol sulfate and indoxyl sulfate) may correlate better with uremic symptoms and mortality than eGFR [12]. The eGFR in the elderly has not been validated and may significantly overestimate the true GFR [13].

It is true our predictive models of outcomes are imperfect and need better validation. However, we make many decisions every day as clinicians with incomplete information and conflicting evidence. We do our best to synthesize all the data and suggest treatment options giving the pros and cons to the patient. We do not recommend treatments that, using our best judgment are ineffective or can cause more harm than good. Certainly for many elderly patients dialysis can cause more harm than good.
Is this patient-centered approach 'ageist'?

It is in the best interests of our patients that age is taken into account for many reasons. The elderly with advanced CKD have a markedly decreased life expectancy, and in an individualized approach to patient care, this is an important factor. The American Board of Internal Medicine 'choosing wisely' campaign included the recommendation by the American Society of Nephrology: 'Don't initiate chronic dialysis without ensuring a shared decision-making process between patients, their families, and their physicians'. The recommendation states '... Survival may not differ substantially for older adults with a high burden of comorbidity who initiate chronic dialysis versus those managed conservatively' [14]. An elderly patient with a low comorbidity burden and good functional status may well get significant benefit from dialysis. When SMD cannot reach a consensus and significant uncertainty exists, then a time-limited trial is recommended $[1,2]$.

This approach where dialysis is not offered to every patient with advanced CKD is based on current best ethical principles [15-18].

\section{References}

1 Renal Physicians Association: Shared Decision-Making in the Appropriate Initiation of and Withdrawal from Dialysis, ed 2. Rockville, Maryland, 2010.

2 Quill TE, Holloway R: Time-limited trials near the end of life. JAMA 2011;306:1483-1484.

3 Rosansky SJ: Early dialysis initiation, a look from the rearview mirror to what's ahead. Clin J Am Soc Nephrol 2014;9:222-224.

4 Slinin Y, Guo H, Li S, Liu J, Morgan B, Ensrud K, Gilbertson DT, Collins AJ, Ishani A: Provider and care characteristics associated with timing of dialysis initiation. Clin J Am Soc Nephrol 2014;9:310-317.

5 Cooper BA, Branley P, Bulfone L, Collins JF, Craig JC, Fraenkel MB, Harris A, Johnson DW, Kesselhut J, Li JJ, Luxton G, Pilmore A, Tiller DJ, Harris DC, Pollock CA; for the IDEAL Study: A randomized, controlled trial of early versus late initiation of dialysis. $\mathrm{N}$ Engl J Med 2010;363:606-619.

6 Rosansky SJ, Eggers P, Jackson K, Glassock R, Clark WF: Early start of hemodialysis may be harmful. Arch Intern Med 2011;171:396-403.

7 Schell JO, Da Silva-Gane M, Germain MJ: Recent insights into life expectancy with and without dialysis. Curr Opin Nephrol Hypertens 2013;22:185-192.
8 O'Connor NR, Kumar P: Conservative management of end-stage renal disease without dialysis: a systematic review. J Palliat Med 2012;15:228-235.

9 Murtagh FE, Marsh JE, Donohoe P, Ekbal NJ, Sheerin NS, Harris FE: Dialysis or not? A comparative survival study of patients over 75 years with chronic kidney disease stage 5 . Nephrol Dial Transplant 2007;22:19551962.

10 Carson RC, Juszczak M, Davenport A, Burns A: Is maximum conservative management an equivalent treatment option to dialysis for elderly patients with significant comorbid disease? Clin J Am Soc Nephrol 2009;4:16111619.

11 Da Silva-Gane M, Wellsted D, Greenshields $\mathrm{H}$, Norton S, Chandna SM, Farrington K: Quality of life and survival in patients with advanced kidney failure managed conservatively or by dialysis. Clin J Am Soc Nephrol 2012;7:2002-2009.
12 Eloot S, Schepers E, Barreto DV, Barreto FC, Liabeuf S, Van Biesen W, et al: Estimated glomerular filtration rate is a poor predictor of concentration for a broad range of uremic toxins. Clin J Am Soc Nephrol 2011;6:12661273.

13 Fontseré N, Bonal J, Navarro M, et al: A comparison of prediction equations for estimating glomerular filtration rate in adult patients with chronic kidney disease stages $4-5$. Effect of nutritional status and age. Nephron Clin Pract 2006;104:c160-c168.

14 http://www.choosingwisely.org/doctorpatient-lists/american-society-of-nephrology/.

15 Moss AH: Ethical principles and processes guiding dialysis decision-making. Clin J Am Soc Nephrol 2011;6:2313-2317.

16 Davison SN: The ethics of end-of-life care for patients with ESRD. Clin J Am Soc Nephrol 2012;7:2049-2057.

17 Skold A, Lesandrini J, Gorbatkin S: Ethics and health policy of dialyzing a patient in a persistent vegetative state. Clin J Am Soc Nephrol 2014;9:366-370

18 Akbar S, Moss AH: The ethics of offering dialysis for AKI to the older patient: time to reevaluate? Clin J Am Soc Nephrol 2014;9: 1652-1656. 